\title{
$O$ atendimento terapêutico às vitimas de violência sexual no município de São José dos Pinhais/ PR: Experiência de implantação do ambulatório sentinela.
}

\section{The therapeutic attendance to victims of sexual violence in São José dos Pinhais/PR: Deployment experience of the sentinel ambulatory.}

\section{El atendimiento terapéutico a las victimas de violencia sexual em el município de São José dos Pinhais/PR: Experiencia de implantación del ambulatório centinela.}

RESUMO: As reflexões do presente artigo tratam de uma importante demanda de saúde pública na atualidade, o atendimento e acompanhamento às vítimas de violência sexual. Objetiva discorrer sobre a implantação do Ambulatório Sentinela, no Município de São José dos Pinhais/PR, como alternativa de atendimento terapêutico às vítimas de violência sexual, bem como, dos agravos decorrentes desta violência. O estudo parte da contextualização dos indicadores da proporção de casos, dos conceitos necessários à compreensão da temática, articulada às diretrizes de atendimento presentes na legislação recente. Na sequencia, é apresentada uma caracterização do Ambulatório, elencando também as alternativas e desafios que se colocam aos profissionais que realizam os atendimentos. Na esfera dos procedimentos metodológicos fez-se uso de pesquisa bibliográfica, estudo de fontes documentais e observação da dinâmica institucional. A principal constatação evidenciada pela pesquisa é de que a implantação de um serviço específico de atendimento às pessoas em situação de violência sexual promove a agilidade das ações de saúde ao centralizálas em um único espaço, maior vinculação dos pacientes ao serviço, reduzindo a exposição e o

1 Assistente Social. Mestre em Ciências Sociais Aplicadas. Especialista em Saúde Pública com Ênfase em Saúde da Família.Secretaria Municipal de Saúde de São José dos Pinhais-PR. E-mail: saguralh@hotmail.com 
constrangimento, além de servir de referência aos demais componentes da rede.

Palavras chave: Saúde Pública, Violência Sexual,Políticas Públicas.

\begin{abstract}
The reflections of this Article adress a major public health demand at the present time, the assistance and monitoring to victims of sexual violence. Aims to discuss the implementation of the Sentinel Ambulatory, in São José dos Pinhais/PR, as an alternative therapeutic attendance to victims of sexual violence as well as of injuries resulting from this violence. The study has its origin at the context of indicators from the proportion of cases, of the concepts needed to understand the theme, articulated to guidelines at the present service in recent legislation. In sequence, the characterization of the ambulatory is presented, also pointing out the alternatives and challenges faced by the professionals who perform the treatments. In the sphere of methodological procedures was made use of bibliographical research, study of documentary sources and observation of institutional dynamics. The main finding evidenced by the survey is that the implementation of a specific service care to people in sexual violence situations promotes agility of health actions by centralizing them in one space, greater linkage of patients to the service, reducing exposure and embarrassment, as well as serve as a reference to the other network components.
\end{abstract}

Keywords: Public Health, Sexual Violence,Public Policies.

RESUMEN: Las reflexiones del presente artículo tratan de una importante demanda de salud pública en la actualidad, la atenciónyel seguimiento de las víctimas de violencia sexual. Pretende disertar sobre la implantación delAmbulatorioCentinela, en elMunicipio de São José dos Pinhais/PR, como una alternativa de atención terapéuticaa lasvíctimas de violencia sexual, así como, de los agravios provenientes de esta violencia. El estudio parte de la contextualizaciónde los indicadores de la proporción de los casos, de los conceptos necesariospara lacomprensión de la temática, articulada con las directricesde atención presentes en la legislaciónreciente. A continuación, se presenta una caracterización del Ambulatorio, señalandotambiénlas alternativas ydesafíos que se anteponen a los profesionales que realizanlas atenciones. En la esfera de los procedimientos metodológicos recurrió a lainvestigación bibliográfica, estudio de fuentes documentales y observaciónde la dinámica institucional. La principal constatación evidenciada por lainvestigaciónes que la implantación de un servicio específico de atencióna las personas en situación de violencia sexual promueve la agilidad de las acciones de salud al centralizarlas en un único espacio, con mayor vinculación de los pacientes al servicio, reduciendola exposiciónysituaciones embarazosas, además de servir como referencia para los demás componentes de la red.

Palabras Claves: Salud Publica. Violencia Sexual. Politicas Publicas.

\title{
INTRODUÇÃO
}

Ao longo do processo histórico e político de desenvolvimento da saúde pública no Brasil, inúmeros desafios têm se colocado aos profissionais executores dos serviços de atendimento. Tratase de uma esfera de intersecção que, ao passo que interfere na qualidade de vida dos indivíduos, é 
tencionada pela influência das mais diversas conjunturas sociais.

A questão do atendimento às vítimas de violência sexual pode ser considerada um importante determinante social da saúde da população na contemporaneidade, uma vez que: "Dentro do conceito ampliado de saúde, tudo o que significa agravo e ameaça à vida, às condições de trabalho, às relações interpessoais e à qualidade da existência faz parte do universo da saúde pública"1.

Além disso, dados da Organização Mundial de Saúde (OMS) estimam que violência sexual atinja cerca de 12 (doze) milhões de pessoas no mundo a cada $a 0^{2}$. No Paraná, dados da Secretaria de Saúde ${ }^{3}$ mostram que entre os anos de 2009 e 2012 foram notificados 23.715 (vinte e três mil setecentos e quinze) casos de violência doméstica e sexual, sendo que, no ano de 2012 esta modalidade foi o agravo à saúdede maior notificação pelos municípios do Estado.

Este panorama é que justifica a relevância da abordagem proposta, pois, sob um ponto de vista epidemiológico a violência sexual atingiu proporções de uma pandemia, ou seja, uma epidemia que tem se alastrado mundialmente. Ela imprime consequências físicas e mentais às vítimas, tais como: risco de contaminação por Doenças Sexualmente Transmissíveis (DST), gravidez indesejada, além de uma sobrecarga e impacto financeiro sobre o Sistema Único de Saúde (SUS): A exemplo se pode mencionar que o SUS gasta, anualmente, entre 8 (oito) e 11 (onze) por cento do teto bruto com as formas de atenção a violência e acidentes ${ }^{4}$.

No que tange especificamente a proteção a crianças e adolescentes, público mais vulnerável a situações de violência, um diagnóstico realizado pelo Conselho Municipal dos Direitos da Criança e do Adolescente (CMDCA) de São José dos Pinhais/PR, em 2012, revelou que o município apresentou deficiências e fragilidades na quase totalidade das áreas relacionadas à proteção, promoção e defesa dos direitos da criança e do adolescente ${ }^{5}$.

Tal configuração é agravada, no país, pela perpetuação de um modelo cultural de base patriarcal e violento que subsiste devido a formas de representação socialque defendem que a esfera familiar não deve sofrer interferências externas. Pode-se exemplificar esta afirmação a partir de estudo realizado por universidades brasileiras que constataram que, em média 6 (seis) a cada 10 (dez) profissionais da área de saúde que identificam violências durante o atendimento, se omitem e não encaminham a denuncia ${ }^{6}$.

Embora as diretrizes do SUS não coloquem a obrigatoriedade de que o atendimento às vítimas seja realizado em serviços específicos, a observaçãoda rotina diária de atendimento dos Hospitais e Unidades de Saúde permite inferir que as equipes, muitas vezes, não conseguem realizar o atendimento a esta demanda adequadamente, ou mesmo, comumente apresentam dúvidas quanto às medidas e encaminhamentos necessários aos casos.

Ao ingressar na composição da equipe multiprofissional de um Ambulatório destinado a atender esta demanda uma questão começou a ser suscitada e motivou o problema desta pesquisa: de que 
maneira um serviço voltado especificamente ao atendimento de pessoas em situação de violência sexual necessita ser estruturado para que possa, efetivamente, estabelecer e desenvolver um fluxo que contemple o adequado acolhimento, abordagem terapêutica, orientação e acompanhamento a estas vítimas?

Portanto, o objeto que se pretende problematizar neste texto é a implantação do Ambulatório Sentinela, no Município de São José dos Pinhais/PR, como uma alternativa de atendimento terapêutico às vítimas de violência sexual, bem como, dos agravos decorrentes desta violência.

Dentre os objetivos destas construções teóricas podem ser destacados: promover a discussão acerca do atendimento às vítimas de violência sexual no âmbito da saúde pública, apresentar possibilidades para execução deste atendimento por meio do trabalho desenvolvido no Ambulatório Sentinela; apresentar os marcos legais, diretrizes, fluxos e sujeitos envolvidos no desenvolvimento das ações profissionais; discorrer sobre os conceitos básicos presentes na abordagem do objeto de estudo.

\section{PERCURSO METODOLÓGICO}

É valido também apresentar, neste momento, o percurso metodológico utilizado nestas reflexões, para as quais se lançou mão de pesquisa bibliográfica, estudo de fontes documentais e da observação.

Assim, a pesquisa bibliográfica «fundamentou teoricamente o objeto de estudo» ${ }^{7}$, possibilitando uma ampliação na percepção dos conceitos, dos espaços de discussão atual, tendências e desafios que se colocam. O estudo das fontes documentais, tais como legislação, planos de ação, fluxos e fluxogramas institucionais, normas operacionais, cadernos temáticos, matrizes pedagógicas, entre outros, forneceu dados e indicadores atualizados, além de explicitar procedimentos, permitindo a caracterização do lócus de atendimento. A observação da dinâmica funcional, das relações entre os profissionais e destes com os usuários, por sua vez, resultou em registros sistematizados que subsidiaram as construções teóricas.

Cabe ressaltar que o estudo não constitui uma avaliação do atendimento realizado pelo ambulatório em termos qualitativos ou quantitativos. Trata-se de apresentar e descrever um processo que está sendo realizado gradativamente em termos teóricos e operacionais, elencando seus avanços, desafios e perspectivas de evolução.

\section{O ATENDIMENTO ÀS VÍTIMAS DE VIOLÊNCIA SEXUAL NA LEGISLAÇÃo BRASILEIRA RECENTE}

Importante contextualizar que o âmbito do atendimento às vitimas de violência sexual na área da Saúde se refere a uma política articulada aos demais segmentos das Políticas Públicas, como a Proteção, Segurança e a Assistência Social. Ela impõe a articulação com outros serviços e pro- 
gramas tanto públicos quanto comunitários, visando sempre à constituição e o fortalecimento das redes de atendimento.

Dito isso, interessa apresentar a fundamentação legal que perpassa a execução do atendimento às vítimas de violência pelos serviços de saúde, as quais, além de se configurar em conquistas sociais têm o potencial de fornecer visibilidade e ampliar o atendimento a esta importante esfera da saúde pública.

Para fins de terminologia, o Novo Código Penal, de 2009, define que os crimes contra a liberdade sexual consistem em: estupro (art. 213), violação sexual mediante fraude (art. 215) e assédio sexual (art. 216a). Criou ainda um capítulo novo, prevendo crimes contra vulnerável.

Estupro de vulnerável (art. 217A): induzir alguém menor de 14 (catorze) anos a satisfazer a lascívia de outrem. (art.218);Praticar, na presença de alguém menor de 14 (catorze) anos, ou induzilo a presenciar, conjunção carnal ou outro ato libidinoso, a fim de satisfazer a lascívia própria ou de outrem. (art. 218A); Submeter, induzir ou atrair à prostituição ou outra forma de exploração sexual, alguém menor de 18 (dezoito) ou que por enfermidade ou deficiência mental, não tem o necessário discernimento para a pratica do ato, facilitá-la, impedir ou dificultar que a abandone ${ }^{8}$.

Em relatório publicado em 2002, a OMS definiu como violência sexual todo o ato sexual não desejado ou ações de comercialização e/ou utilização da sexualidade de uma pessoa mediante qualquer tipo de coerção ${ }^{2}$.

Neste ponto, é importante destacar que conceituar o fenômeno da violência sexual é uma tarefa complexa. Lemer ${ }^{9}$ observa que o termo abuso sexual abrange praticas que diferem bastante entre si na esfera dos riscos à saúde e consequências, propõe uma divisão didática que, embora se constitua numa simplificação, pode servir de referência aos profissionais envolvidos no atendimento a esta demanda. $\mathrm{O}$ autor divide as situações de abuso sexual em três diferentes grupos: "exploração sexual, abuso sexual agudo e abuso sexual crônico".

O que caracteriza a exploração sexual, para o autor, é o componente financeiro envolvido na pratica sexual; no abuso sexual agudo tem-se a ocorrência de um episódio único em um tempo de exposição relativamente curto, sendo comum o uso da violência física. Já as situações de abuso sexual crônico são as mais frequentes e, de maneira geral, ocorrem dentro do ambiente familiar, o que faz com que esta seja a modalidade de intervenção mais difícil.

Retrocedendo às conquistas legais dos últimos anos, deve-se destacar que todas as normatizações que serão apresentadas estão pautadas em acordos internacionais de que o Brasil é signatário e também na legislação nacional: Constituição Federal de 1988, Estatuto da Criança e do Adolescente de 1990 e no Código Penal.

$\mathrm{Na}$ esfera das políticas de saúde um importante marco normativo foi instituído por meio da 
Portaria MS/GM nº737/2001, do Ministério da Saúde, na qual foi estabelecida a Política Nacional de Redução da Morbimortalidade por acidentes e violência ${ }^{10}$. Esta regulamentação estabeleceu as diretrizes e responsabilidades institucionais, estando contempladas as medidas constitutivas da promoção à saúde e prevenção aos acidentes e violências.

Outra importante lei aprovada foi a de notificação compulsória dos casos de violência contra mulheres $^{11}$, pessoas idosas ${ }^{12}$, crianças e adolescentes ${ }^{13}$. Atualmente, a notificação é obrigatória a todos os profissionais de saúde, devendo ser notificados todos os casos de violência que envolvam os grupos acima citadose as demais violências de acordo com a sua natureza ${ }^{14}$. A notificação deve ser preenchida pelo profissional que suspeitar ou confirmar a violência, sem prejuízo a intervenção dos demais profissionais.

No que tange o instrumento da notificação é necessário inserir algumas ponderações: em alguns casos, os profissionais ao não compreenderem a finalidade e alcance da mesma, podem acabar a utilizando como mecanismo coercitivo junto aos usuários. Entretanto, deve-se destacar que a notificação não é um instrumento de punição e não tem a finalidade de servir a coerção; ao encaminhar a notificação aos setores responsáveis o profissional de saúde insere aquela demanda no âmbito do trabalho da rede, porém, não determina os moldes da intervenção destes.

A notificação da violência proporciona visibilidade ao problema, possibilitando um diagnóstico da realidade que pode contribuir para a formulação das Políticas Públicas de atendimento. Além disso, os casos inseridos na Rede de Proteção passam a ter atendimento e acompanhamentos constantes, que podem contribuir para a redução das consequências da violência, assim como prevenir novos episódios ${ }^{15}$.

Deve-se atentar também que o Estatuto da Criança e do Adolescente ${ }^{13}$ em seu art. 13 coloca a obrigatoriedade de que os casos de suspeita ou confirmação de maus tratos a crianças e adolescentes devam ser obrigatoriamente, comunicados ao Conselho Tutelar.

Avançando, a Portaria n 936 de 19 de maio de 2004, do Ministério da Saúde/ Gabinete do Ministro dispõe sobre a estruturação de Rede Nacional de Prevenção à violência e Promoção da saúde, implantação e implementação de Núcleos de Prevenção à Violência em Estados e Municípios ${ }^{16}$.

É necessário destacar que a fundamentação do Ambulatório Sentinela se encontra diretamente relacionada a esta normativa, pois, o planejamento técnico operativo do serviço prevê que ele se constitua em referência, não apenas no atendimento terapêutico, mas também no desenvolvimento e participação nas ações de promoção à saúde e prevenção da violência, com participação nas redes intersetoriais e conselhos locais.

Outro importante marco normativo foi o Decreto 8.086 de 30 de agosto de 2013 que instituiu o Programa Mulher: Viver sem Violência, com objetivo de "integrar e ampliar os serviços públicos existentes voltados às mulheres em situação de violência, mediante a articulação dos atendimentos 
especializados no âmbito da saúde, da justiça, da rede socioassistencial e da promoção da autonomia financeira" 17.

Por sua vez, o Decreto 7958 de 13 de março de 2013, trouxe como inovação as diretrizes para o atendimento humanizado às vítimas de violência sexual pelos profissionais de Segurança Pública e da Rede de Atendimento do SUS ${ }^{18}$. Estabeleceu também as competências do Ministério da Justiça e do Ministério Saúde, com vistas a sua implementação.Já a Portaria 2.415 de 07 de novembro de 2014 incluiu o procedimento Atendimento Multiprofissional para a Atenção Integral às Pessoas em Situação de Violência sexual e todos os seus atributos na tabela de procedimentos, Medicamentos, Órteses e Próteses e Materiais Especiais do SUS ${ }^{19}$, enquanto a portaria 616 de 18 de julho de 2014 inseriu o serviço 165: “Atenção Integral à saúde de Pessoas em situação de Violência Sexual, alterando a tabela de serviços especializados do Sistema de Cadastro Nacional de estabelecimentos de saúde $(\mathrm{SCNES})^{20}$.

Neste sentido, em 2015, foi aprovada também a Norma Técnica de Atenção Humanizada às Pessoas em Situação de Violência Sexual com Registro de informações e coletas de Vestígios ${ }^{21}$, além das Portarias 1662 de 02/10/2015²2 e 288 de 25/03/2015²3.

A lei 12845 , de $1^{\circ}$ de agosto de 2013 , prevê o atendimento obrigatório e integral às vítimas de violência sexual em todos os hospitais integrantes da rede do SUS, destaca, ainda, em seu inciso II que tal atendimento deve compreender os seguintes serviços: “amparo médico, psicológico e social imediatos $^{24 \%}$.

Merecem destaque, ainda, a Portaria 485, de $1^{\circ}$ de abril de 2014, que redefine o funcionamento do Serviço de Atenção às Pessoas em Situação de Violência Sexual no âmbito do SUS ${ }^{25}$, Portaria 1271, de 6 de junho de 2014 e a Norma técnica de prevenção e tratamento a agravos resultantes de violência sexual contra mulheres e adolescentes ${ }^{26}$.

No âmbito Municipal, a Secretaria Municipal de Saúde de São José dos Pinhais/PR, tendo como referencial as normativas anteriormente elencadas, adota as seguintes diretrizes para o acolhimento, atendimento e encaminhamento de pessoas em situação de violência sexual:

I - garantia de que o planejamento das ações de prevenção, atenção as vítimas seja realizada de forma articulada, integrada com a rede de proteção e a rede de serviços públicos e privados, definindo-se os papéis e responsabilidades, considerando a complexidade e multicausalidade do fenômeno; II - Cumprimento aos princípios das políticas formuladas e estabelecida pela Constituição Federal, convenções internacionais, ECA, LOAS, SUAS, SUS, resoluções do CMDCA e outros; (...) IV - Respeito e credibilidade às diversas formas de manifestação e expressão das vítimas; (...) VII - respeito à integralidade das pessoas vítimas de violência e a seu grupo familiar, respeitando-os como sujeitos de direitos; (...) VIII - incentivo, implantação e implementação de 


\section{serviços e programas de prevenção, atenção e de proteção as vítimas de violência} e /ou grupo familiar, garantindo o atendimento intersetorial ${ }^{27}$.

É inegável que a evolução das concepções sociais e as conquistas legais influenciaram de maneira significativa na construção do modelo atual de atendimento às vítimas de violência sexual. Porém, entende-se ser necessário avançar no sentido de tornar estas diretrizes uma realidade presente no dia a dia das instituições que recebem estes pacientes. Neste contexto, se inserem alternativas de atendimento como o realizado pelo Ambulatório Sentinela que será mais bem detalhado na sequencia.

\section{Caracterização do Ambulatório Sentinela}

O Ambulatório Sentinela, inaugurado em janeiro de 2015, é vinculado ao Departamento de Atenção Primária e Especializada a Saúde da Secretaria Municipal de Saúde de São José dos Pinhais/PR. Sua implantação se encontra pactuada no Plano Municipal de Enfrentamento a Violência Doméstica e Sexual contra a Criança e o Adolescente.

Constitui-se de um espaço destinado ao atendimento terapêutico de pessoas que se encontram em situação de violência sexual São atendidas crianças e adolescentes, mulheres, idosos e portadores de deficiência que foram vítimas de violência sexual no último ano.

Importante enfatizar que são atendidos pelo Ambulatório os casos confirmados de violência sexual. Porém, esta comprovação não se refere a exames ou laudos, pois, o que se leva em consideração é o relato da vítima e, quando esta não pode se expressar, são considerados relatos de familiares, o conjunto de circunstâncias, características ou comportamentos que sejam indicativos do abuso.

De acordo com o fluxo de atendimento do serviço, os princípios norteadores das ações da equipe multiprofissional são: o acolhimento humanizado, escuta atenta, abordagem adequada, orientação educativa tendo como parâmetros os princípios da ética profissional, respeito à privacidade e sigilo.

O espaço físico do ambulatório compreende uma recepção, quatro salas para atendimentos aos pacientes, sendo uma delas equipada com materiais para atendimento ginecológico, sala de espera e almoxarifado.

A equipe multiprofissional que realiza os atendimentos no local é constituída por: uma coordenadora, duas Psicólogas, uma Assistente Social e uma Médica Ginecologista. Os pacientes também recebem atendimento Psiquiátrico quando necessário, porém este profissional, embora vinculado ao Ambulatório, realiza os atendimentos no Centro Municipal de Especialidades (CEM).

O encaminhamento destes pacientes é realizado a partir do Protocolo de Encaminhamento de Pessoas em Risco Social (RS)- formulário de referência e contra referência - pelos integrantes 
da Rede de Atendimento Municipal sendo estes: Hospital e Maternidade Municipal, Unidades Básicas de Saúde (UBS), Unidades de Pronto Atendimento (UPA), Delegacia da Mulher e do Adolescente (DMA), Conselho Tutelar (CT), Centro de Referência Especializado de Assistência Social (CREAS), Centros de Referência da Assistência Social (CRAS), Centro de Atendimento Psicossocial (CAPS) e outros.

O profissional de referência no Ambulatório para os serviços da rede é o Assistente Social, o qual recebe o relato das situações e o Protocolo de Risco Social, realiza a triagem dos casos, orienta quanto aos fluxos e procedimentos. Além disso, quando necessário, estabelece contato com outros serviços e instituições para um maior conhecimento das demandas recebidas.

Dentre os serviços disponibilizadosaos pacientes tem destaque: o atendimento Psicológico, destinado a orientações e tratamento terapêutico às consequências do abuso; atendimento de Serviço Social, com vistas ao acolhimento, orientações e acompanhamento; consulta Ginecológica para o tratamento dos agravos decorrentes da violência sofrida e consulta Psiquiátrica para fins de tratamento.

$\mathrm{O}$ atendimento de Psicologia tem início com uma triagem para conhecimento e aprofundamento da situação. Quando os pacientes são crianças,adolescentes, ou com alguma limitação cognitiva este primeiro atendimento será sempre com um responsável legal, sem a presença do paciente.

De maneira geral, os atendimentos são semanais, em alguns casos podem ser realizados quinzenalmente. Em casos em que o paciente faltar reiterada e injustificadamente, ou em casos de desistência do tratamento, o local que realizou o encaminhamento é de pronto, comunicado.

Cabe destacar que, em algumas situações, a equipe avalia como necessária também a inclusão de outros familiares no acompanhamento terapêutico. São situações em que o familiar, apesar de não ter sido a vítima direta do abuso, apresenta grande dificuldade emocional em lidar com a situação, ou mesmo, manifesta posturas inadequadas ao se relacionar com a vítima, como por exemplo, sendo omisso e negligente ou culpabilizando à vítima pela violência. Nestes casos, o familiar passa a ser acompanhado por outro Psicólogo da equipe.

Neste sentido, os atendimentos realizados pela equipe não possuem um formato padrão. Como a variabilidade de situações é ampla, as intervenções vão se construindo na dinâmica de interação com cada paciente em específico, assim:

As diferençasde estruturação familiar, das características da personalidade dos envolvidos e seus históricos pessoais, da cronologia dos eventos e da natureza do abuso tornam cada caso uma situação particular, o que dificulta a padronização ou generalização das condutas de atendimento. A compreensão da singularidade de cada caso é fundamental para a adequação do tratamento às necessidades dos envolvidos. Neste caso, a qualidade mais importante para um atendimento adequado é a adaptabilidade da equipe profissional ${ }^{7}$. 


\section{$204 / /$}

$\mathrm{Na}$ esfera da adequação do tratamento às demandas apresentadas pelos pacientes e da adaptabilidade da equipe às alterações surgidas ao longo dos acompanhamentos, vale ressaltar que a equipe mantém um processo constante de avaliação das ações e discussão conjunta dos casos.

Faz se necessário mencionar também que,embora seja comum aos órgãos de Segurança e do Judiciário buscarem respaldo para suas decisões na avaliação de profissionais que realizam atendimento às vítimas de violência, os profissionais da equipe do Ambulatório, devido a natureza e objetivos da intervenção em saúde, não emitem laudos ou pareceres referentes aos atendimentos, apenas declarações comprovando o acompanhamento.

Após 12 (doze) meses de acompanhamento, os pacientes passam por reavaliação recebendo alta temporária ou permanente. Os casos de alta a pedido do paciente são discutidos junto a este e a equipe multiprofissional.

No que se refere à articulação com os demais atores e instituições integrantes da rede de atendimento tem destaque o trabalho realizado junto ao Centro de Referência Especializado de Assistência Social, por meio do Serviço de Proteção e Atendimento Especializado às famílias e Indivíduos(PAEFI), sendo que, mensalmente, as equipes se reúnem para discussão dos casos em atendimento e apresentação de novas situações.

Desta forma, a relação entre às áreas da Saúde e da Assistência Social se processa de maneira complementar, uma vez que, o CREAS atua no contexto de risco e vulnerabilidade das famílias, avaliando e intervindo na dinâmica destas, através de visitas domiciliares, grupos de apoio, orientações jurídicas, enfatizando a prevenção a novas situações ou episódios de violência, acessando, quando necessário, medidas de proteção e de acolhimento institucional.

No âmbito da Segurança Pública o Ambulatório mantém interação com a Delegacia da Mulher e do Adolescente em um fluxo de troca de informações, recebendo encaminhamentos para inclusão das vítimas de violência sexual no atendimento, bem como, encaminhando também os pacientes que necessitam da intervenção daquele setor.

Tal interação também ocorre, frequentemente, com o Sistema de Garantias de Direitos: Ministério Público, Vara da Infância e Juventude e outras instituições do Poder Judiciário, bem como, com os Conselhos Tutelares, Conselhos de Direitos e de Políticas Setoriais.

Considerando que cada área do conhecimento envolvida no atendimento às vítimas de violência sexual possui uma terminologia, linguagem, metodologia e procedimentos que lhe são peculiares, o papel do Ambulatório também envolve mediação e articulação entre os diferentes serviços, buscando evitar que as ações ocorram de maneira pontual, redundantes ou contraditórias entre si.

No que se refere aos aspectos positivos da implantação do serviço, merecem ser destacados: possibilitar uma maior atenção à privacidade dos pacientes, evitando-se a exposição e o constran- 
gimento; maior agilidade na viabilização do atendimento terapêutico, bem como, ao tratamento e acompanhamento dos agravos resultantes da violência, maior vinculação dos pacientes e familiares ao serviço, centralização dos vários aspectos do acompanhamento de saúde em um único local.

Além disso, o ambulatório tem servido como referência aos demais componentes da rede de atenção na esfera de atendimento aos casos de violência sexual no município, prestando esclarecimentos e orientações acerca dos fluxos de atendimento e demais procedimentos.

\section{Perspectivas e desafios às ações profissionais no atendimento aos casos de violência sexual}

A experiência histórica tende a revelar que evolução do modelo de atendimento não opera mudanças imediatas nas práticas sociais e profissionais. Por esta razão, o aprofundamento referente à implantação de novos paradigmas tende a evidenciar as limitações que se colocam para a operacionalização das ações.

No campo da saúde pública se pode enumerar alguns entraves a atuação dos profissionais no atendimento e enfrentamento as situações de violência sexual, tais como: a concepção de que a violência é um fenômeno secundário no processo saúde-doença; visão de que a prevenção e o enfrentamento a violência deve estar restrito a determinados grupos profissionais; perspectiva de que o setor de saúde é apenas um reparador de danos das situações de violência; não compreensão do campo da saúde como uma política que está articulada a outras políticas públicas, instituições emovimentos sociais; naturalização ou banalização do sofrimento, preconceitos ou julgamentos de valores.

Além disso, ao se deparar com um relato de violência alguns profissionais incorrem, erroneamente, em uma postura investigativa fazendo perguntas exaustivas e desnecessárias, desrespeitando a intimidade e a privacidade da vítima da violência. Em determinados casos, busca-se inclusive, justificar e explicar a violência sofrida tendo como parâmetro o comportamento da vítima.

Sabe-se que, ao realizarem suas intervenções, estes indivíduos não estão isentos de imprimir subjetividade a estas, através de suas experiências, valores, crenças e visão de mundo. O profissional na interação que realiza também classifica, define, reprova, enfim atribui sentido e valor às situações a partir de seus próprios valores.

Para além das rotinas e procedimentos operacionais estas são questões que precisam ser problematizadas junto aos profissionais dos serviços de saúde e enfrentadas cotidianamenteOs desafios que perpassam a execução das ações profissionais não são apenas de cunho normativo ou político, mas impõem também uma mudança na maneira de olhar para o fenômeno da violência sexual: "O Sistema Único de Saúde (SUS) tem necessidade de avançar no que se refere à premissa da proteção dos direitos humanos e da cidadania de pessoas que sofreram ou sofrem violências ${ }^{28}$ ". 
Uma das frentes em que a equipe do Ambulatório Sentinela pretende ampliar sua atuação é justamente na promoção de espaços de discussão e construção coletiva junto aos atores da rede de atendimento local. Neste sentido, já estão sendo realizados encontros com os profissionais das diferentes instituições do município para troca de informações, discussão de demandas e procedimentos. Da mesma forma, faz parte do planejamento operacional do serviço tornar o ambulatório um espaço onde possam ocorrer reuniões de rede, estudos e outras atividades formativas.

Neste sentido, entende-se que tão importante quanto implantar um serviço de atendimento é fazer com este seja conhecido, acessado e, sobretudo, que esteja em constante interação com as demais instituições de atendimento.

A equipe iniciou também um trabalho com grupo de familiares dos pacientes em acompanhamento terapêutico, abrindo espaço para que estes possam se aproximar mais da equipe, trocar experiências, colocarem suas dúvidas, angustias e expectativas. O pressuposto é de que o acompanhamento não pode se restringir apenas à vítima da violência, pois, conforme observa Araujo ${ }^{29}$ (2002) é necessário conhecer também como os outros familiares envolvidos pensam, sentem e se relacionam como problema e de que recursos dispõem para interferir na realidade familiar.

\section{CONSIDERAÇÕES FINAIS}

$\mathrm{O}$ atendimento e acompanhamento às vítimas de violência sexual, comumente tem início nos serviços de saúde. Entretanto, trata-se de uma esfera de intervenção complexa, em que os profissionais, muitas vezes, sentem-se inseguros e desconfortáveis no momento de agir.

É digna de nota, nos últimos anos, uma intensa mobilização social e política no sentido de aprovarem-se leis, decretos e outras regulamentações, além da publicação de normas técnicas e cadernos de procedimentos, promovendo a instrumentalização dos profissionais responsáveis pelos atendimentos nas instituições.

No entanto, é de se ressaltar que o conjunto de regulamentações não constitui uma formula mágica que se molda à realidade de maneira harmoniosa. Sendo assim, é fundamental a construção de estratégias de atendimento, seja no interior dos serviços em funcionamento, seja por meio da criação de espaços específicos para esta modalidade, que contem com uma equipe sensibilizada e instrumentalizada para o acolhimento, escuta e abordagem adequada a esta demanda de saúde.

Assim, a busca por responder aos questionamentos da pesquisa apontou para a constatação de que, desenvolver um fluxo de atendimento efetivo às vítimas de violência sexual, impõe tanto a viabilização das condições objetivas para a realização de procedimentos, adoção de normas e parâmetros consistentes, quanto um processo permanente de formação e educação ético-profissional, atento aos princípios da dignidade humana. 
Com esta finalidade é que se propôs apresentar a implantação do Ambulatório Sentinela, configurando um espaço que concentra os diversos aspectos do atendimento em saúde, no contexto da violência sexual, possibilitando o início imediato da intervenção terapêutica e tratamento aos agravos, evitando que os pacientes tenham que transitar entre os mais variados locais, repetindo seus relatos, se expondo ou sofrendo constrangimentos.

\section{REFERÊNCIAS BIBLIOGRÁFICAS}

1. MINAYO, M.C.S e SOUZA, E.R. É possível prevenir a violência? Reflexões a partir do campo da Saúde Pública. Ciência e Saúde Coletiva. 4(1): 7-32, 1999.

2. KRUG. E.G.et.al. World Report on Violence and Health. Geneva. Word Hearth Organization, 2002 .

3. PARANÁ. Secretaria de Estado da Saúde do Paraná. Caderno temático de vigilância de violências e acidentes no Paraná. - Curitiba: SESA/SVS, 2014.

. BRASIL. Ministério da Saúde. Secretaria de Atenção à Saúde. Atenção integral para mulheres e adolescentes em situação de violência doméstica e sexual: matriz pedagógica para a formação de redes. 1. Ed. Brasília: Editora do Ministério da Saúde, 2011.

5. SÃO JOSÉ DOS PINHAIS. Conselho Municipal dos Direitos da Criança e do Adolescente. Plano de Ação - 2013. Disponível em:http://conselhos.sjp.pr.gov.br/. Acesso em 29.jul.2015.

6.AGÊNCIA BRASIL. Medo de represália leva profissionais de saúde a deixar de denunciar casos suspeitos de violência contra crianças. Disponível em: http://www.ebc.com.br/noticias/ saude/2013/03/medo-de-represalia-leva-profissionais-de-saude-a-deixar-de-denunciar-casos. Acesso em 05.ago.2015

7. LIMA, T.C.S e MIOTO, R.C.T. Procedimentos metodológicos na construção do conhecimento científico: a pesquisa bibliográfica. Revista Katálysis, vol.10. Florianópolis, 2007.

8. BRASIL. Presidência da República. Lei No 12015 de 7 de agosto de 2009. Altera o titulo VI da parte Especial do decreto Lei $\mathrm{n}^{\circ} 2.848$, de 7 de dezembro de 1940 - Código Penal, e o art. $1^{\circ}$ da Lei $\mathrm{n}^{\circ} 8072$, de 25 de julho de 1990, que dispõe sobre os crimes hediondos, nos termos do inciso XLIII do art. $5^{\circ}$ da Constituição Federal e revoga a Lei $n^{\circ} 2.252$, de $1^{\circ}$ de julho de 1954, que trata da corrupção de menores. Disponível em http://www.planalto.gov.br/ccivil 03/LEIS/L12015.htm. Acesso em: 25 jul. 2015.

9. LEMER, T. A atuação do profissional de saúde frente a situações de abuso sexual. In:MALLAK, 1.S. e VASCONCELOS, M G.(ORG).Compreendendo a violência sexual em uma perspectiva multidisciplinar- São Paulo: fundação Orsa Criança e vida, 2002. 
10. BRASIL. Ministério da Saúde. Secretaria de Vigilância em Saúde. Política nacional de redução da morbimortalidade por acidentes e violências. 2. Ed. Brasília: editora do Ministério da Saúde, 2005.

11. BRASIL. Presidência da República. Lei Nº 10778, de 24 de novembro de 2003. Estabelece a notificação compulsória, no território nacional, do caso de violência contra a mulher que for atendida nos serviços de saúde públicos ou privados. Disponível em: http://www.planalto.gov.br/ ccivil 03/LEIS/L10778.htm Acesso em 29.jul.2015.

12. BRASIL. Lei $\mathrm{N}^{\circ} 10741$ de 01 de outubro de 2003. Dispõe sobre o Estatuto do Idoso e dá outras providências. Disponível em: http://www.planalto.gov.br/ccivil 03/leis/2003/L10.741. htmAcesso em 29.jul.2015.

13. BRASIL. LEI No 8069, de 13 de Julho de 1990. Estatuto da Criança e do Adolescente. Disponível em: http://www.planalto.gov.br/ccivil_03/LEIS/L8069.htm. Acesso em 02 ago.2015.

14. BRASIL. Ministério da Saúde. Portaria No 1.271 de 06 de junho de 2014. Define a lista Nacional de Notificação Compulsória de doenças, agravos e eventos de saúde pública nos serviços de saúde públicos e privados em todo o território nacional, nos termos do anexo, e dá outras providências. Disponível em: http://bvsms.saude.gov.br/bvs/saudelegis/gm/2014/ prt1271_06_06_2014.html. Acesso em 29.jul.2015.

15. CURITIBA. Secretaria Municipal de Saúde. Protocolo da Rede Proteção a Criança e ao Adolescente em situação de risco para a violência. 3 Ed. ver. E atual- Curitiba, 2008.

16. MINISTÉRIO DA SAÚDE.PORTARIA No 936, DE 19 DE MAIO DE 2004. DISPÕE SOBRE A ESTRUTURAÇÃO DA REDE NACIONAL DE PREVENÇÃO DA VIOLÊNCIA E PROMOÇÃO DA SAÚDE E A IMPLANTAÇÃO E IMPLEMENTAÇÃO DE NÚCLEOS DE PREVENÇÃO À VIOLÊNCIA EM ESTADOS E MUNICÍPIOS. DISPONÍVEL EM HTTP:// BVSMS.SAUDE.GOV.BR/BVS/SAUDELEGIS/GM/2004/PRT0936_19 05 2004.HTML. ACESSO EM 29.JUL.2015.

17.BRASIL. Presidência da República. Decreto No 8.086 de 30 de agosto de 2013. Institui o Programa Mulher: viver sem violência e dá outras providências. Disponível em http://www. planalto.gov.br/ccivil_03/_Ato2011-2014/2013/Decreto/D8086.htm. Acesso em 05.abri.2016

18. BRASIL. Presidência da República. Decreto No 7958, de 13 de março de 2013. Estabelece diretrizes para o atendimento às vítimas de violência sexual pelos profissionais de segurança pública e da rede de atendimento do Sistema Único de Saúde. Disponível em:http://www.planalto. gov.br/ccivil_03/DECRETO/D7958.htm. Acesso em: 05 abr. 2016.

19. BRASIL. Ministério da Saúde. Portaria No 2.415 de 07 de novembro de 2014. Inclui o 
procedimento Atendimento Multiprofissional para a Atenção Integral às Pessoas em Situação de Violência sexual e todos os seus atributos na tabela de procedimentos, Medicamentos, Órteses/ Próteses e Materiais Especiais do SUS. Disponível em http://bvsms.saude.gov.br/bvs/saudelegis/ gm/2014/prt2415 $07 \quad 11$ 2014.html. Acesso em 05.abr.2016

20. BRASIL. Ministério da Saúde. Portaria No 618 de 18 de julho de 2014. Altera a tabela de serviços especializados do Sistema de Cadastro Nacional dos Estabelecimentos de Saúde (SCNES) para o serviço 165 Atenção Integral à Saúde da Pessoa em Situação de Violência Sexual e dispõe sobre regras para seu cadastramento. Disponível em: http://www2.unifesp.br/proex/novo/eventos/ eventos14/maistrinta/docs/legislacao/portaria_6182014.pdf. Acesso em 04.abr.2016.

21. BRASIL. Ministério da Saúde. Norma Técnica de Atenção Humanizada às Pessoas em Situação de Violência Sexual com Registro de informações e coletas de Vestígios. Disponível em http://www.hc.ufpr.br/arquivos/07566 norma atendimento_vs_2015.pdf. Acesso em 04.abr.2016.

22. BRASIL. Ministério da Saúde. Portaria No 1.662 de 02 de outubro de 2015. Define critérios para habilitação para realização de Coleta de Vestígios de Violência Sexual no Sistema Único de Saúde (SUS), inclui habilitação no Sistema de Cadastro Nacional dos estabelecimentos de Saúde (SCNES) e cria procedimento específico na Tabela de Procedimentos, medicamentos e Órteses e Próteses e Materiais Especiais. Disponível em http://www.lex.com.br/legis 27028569 PORTARIA N 1662 DE 2 DE_OUTUBRO_DE 2015.aspx. Acesso em 04.abr.2016.

23. BRASIL. Portaria Interministerial No 288 de 25 de março de 2015. Estabelece orientações para a organização e integração do atendimento às vítimas de violência sexual pelos profissionais de segurança pública e pelos profissionais de saúde do Sistema Único de Saúde (SUS) quanto à humanização do atendimento e ao registro de informações e coleta de vestígios. Disponível em http:// www.conselhodacrianca.al.gov.br/sala-de-imprensa/noticias/2015/abril/portaria-interministerialno-288-de-25-de-marco-de-2015-1. Acesso em 05.abr.2016.

24.BRASIL. Presidência da República. Lei No 12.845 , de $1^{\circ}$ de agosto de 2013. Dispõe sobre o atendimento obrigatório e integral de pessoas em situação de violência sexual. Disponível em: http://www.planalto.gov.br/ccivil 03/LEIS/L12845.htm. Acesso em: 22 jul. 2015.

25. BRASIL. Ministério da Saúde. PortariaN485, de $1^{\circ}$ de abril de 2014. Redefine o funcionamento do Serviço de Atenção às Pessoas em Situação de Violência Sexual no âmbito do Sistema Único de Saúde (SUS). Disponível em http://bvsms.saude.gov.br/bvs/saudelegis/gm/2014/ prt0485_01_04_2014.html.

26.MINISTÉRIO DA SAÚDE. Secretaria de Atenção à Saúde. Prevenção e tratamento dos agravos resultantes da violência sexual contra mulheres e adolescentes: norma técnica. BRASIL. Ministério da Saúde. Secretaria de Atenção à Saúde. 2. Ed. Brasília: Ministério da Saúde, 2012. 
27. DEPARTAMENTO DEATENÇÃO PRIMÁRIAE ESPECIALIZADAÀ SAÚDE. Diretrizes de atendimento. Documento impresso. Secretaria Municipal de Saúde, São José dos Pinhais, 2015.

28. BRASIL. Ministério da Saúde. Secretaria de Atenção à Saúde. Aspectos jurídicos do atendimento às vitimas de violência sexual: perguntas e respostas para profissionais de saúde. 2 . Ed. Brasília: Editora do Ministério da Saúde, 2011. 48p.

29. ARAÚJO, Maria de Fátima. Violência e abuso sexual na família. Revista Psicologia em Estudo. Maringá, v.7, n 02 jul./dez. 2002.

Artigo apresentado em 02-09-15

Artigo aprovado em 06-02-16 Artigo publicado no sistema em 21-02-16 